\title{
El arbitrio de tierras de 1622 y el debate sobre las propiedades y los derechos coloniales de los indios/
}

\author{
The Lands Tax of 1622 and the Debate over Property \\ and the Colonial Rights of the Indians
}

\author{
Luis Miguel Glave
}

Universidad Pablo de Olavide, Sevilla

Este artículo analiza un arbitrio sobre la venta de tierras de 1622, situándolo en el extenso debate acerca de la licitud de la enajenación y composición de propiedades comenzado a finales del siglo XVI. Se estudia la coyuntura de presión sobre los recursos de los naturales y las opciones de defensa de los mismos, procurando resaltar el diálogo entre la política metropolitana, que buscaba ampliar recursos monetarios en tiempo de necesidad, y las discrepancias internas del reino andino en pleno proceso de cambios administrativos $y$ legales que intentaban responder a esa demanda imperial.

Palabras Clave: Composiciones de tierras; Arbitrios; Propiedades agrícolas; Despojos a los indios; Derechos de propiedad; Pareceres jurídicos.

This article analyses the 1622 tax on the sale of lands within the context of the broad debate regarding the lawfulness of the sale and composition of properties, initiated at the end of the sixteenth century. The opportunity to press upon the natives' resources is studied, as well as the defensive measures available to them, while striving to call attention to the dialogue between metropolitan policy - which sought to increase monetary resources in times of need - and discrepancies within the Andean kingdom at a time of legal and administrative changes that attempted to respond to imperial demands.

KEYwORDS: Composition of lands; Tariffs; Agricultural property; Spoliation of Indians; Property rights; Legal opinions. 
En 1622, un hombre de armas pero a la vez de pluma fácil, probablemente recogiendo la experiencia de las observaciones de sus andanzas y en su intento de establecerse en alguna posición del orden administrativo colonial, presentó un arbitrio sugiriendo las ventajas de vender las tierras sobrantes en el territorio del virreinato peruano. Se sumaba de este modo a una corriente de pensamiento llamada arbitrismo, que en ese momento se manifestaba tanto en la metrópoli como en los reinos indianos. Si bien el arbitrio no prosperó, desde entonces se abrió la puerta para sucesivas campañas de recaudación de rentas a través de las enajenaciones de tierras que se atribuyeron intrínsecamente al rey. Lo que llama la atención es que estas propuestas se realizaran al cabo de relativamente poco tiempo de que se hubiera dado el primer paso para la consolidación de un amplio mercado de tierras, a partir de las primeras composiciones encargadas al virrey marqués de Cañete.

\section{Antecedentes: las grandes políticas económicas de fin del siglo XVI y el mercado de tierras}

La formación de un mercado de productos agrarios resultó paralela al establecimiento de otro de tierras, que sentó las bases de las propiedades agrarias que se llamarían luego haciendas. ${ }^{1}$ El impulso más grande que recibieron fue cuando la corona decidió dar una ley de venta de tierras en el año 1591. El proceso de consolidación de mercados agrícolas en el siglo XVI marchó paralelo a la expansión del capital minero y a la decadencia de la producción de la economía campesina, exhausta por la pérdida de gente y de recursos. La renta de la encomienda se monetizó como un mecanismo de coacción al trabajador campesino para asalariarse. Las ciudades crecieron mucho, sobre todo las mineras, demandando más medios de producción y de subsistencia que, dadas las limitaciones de la producción campesina, debieron ser elaborados internamente por los españoles. Así las cosas, la tierra comenzó a adquirir un carácter de mercancía, aunque limitadamente por la relativa facilidad de adquirirla entonces sin pasar por el mercado.

Dos fueron los períodos que mostró el proceso de consolidación de propiedades territoriales: en primer lugar, el desordenado conjunto de formas legales o ilegales de adquirir tierras en propiedad, que buscaban

1 Sobre la formación de los mercados de tierra y productos agrícolas, véase Glave, 2009. 
conseguir distintos «pedazos» en áreas más extensas y, preferentemente, planas y de riego. En segundo lugar, ya formadas las propiedades y mostrándose incontenible el acaparamiento de tierras, el momento de las «composiciones» de tierras entre el rey y los hacendados interesados. ${ }^{2}$

El espacio temporal de los mecanismos originales de acceso a la tiera se concentró básicamente en la segunda mitad del siglo XVI y principios del XVII, lo que no impidió que aquellos se reprodujesen en otras condiciones cuando ya se habían formado grandes espacios territoriales en un solo cuerpo. Lo que encierran las transacciones tipificadas anteriormente es un proceso que surgió desde abajo, por iniciativas lentamente consolidadas de una nueva clase de hacendados. La corona no había hasta entonces tenido la voluntad ni la posibilidad de legislar un proceso que no patrocinó directamente.

\section{El nacimiento de la propiedad privada de la tierra: las composiciones}

Las cosas comenzaron a cambiar a partir de una real cédula de 1591 , cuyo cumplimiento se encomendó al virrey del Perú García Hurtado de Mendoza, marqués de Cañete. Se inició a partir de este momento el período de las composiciones. Como la corona tenía problemas fiscales por el incremento de los gastos defensivos, y viendo que la tierra entraba en un cierto mercado para el que no había habido una clara disposición de legislar, finalmente decidió financiarse mediante la venta de su derecho eminente a la tierra a los propietarios de hecho. Para eso, se dispuso la realización de «visitas» para medir las propiedades y vender títulos de propiedad a los poseedores que enseñaran instrumentos públicos en los que se refrendara la forma en la que habían adquirido las extensiones. Asimismo, se mandó vender las tierras que, de acuerdo a la medición, resultaran como «demasías» respecto a los instrumentos públicos mostrados, y rematar las «sobras» de indios una vez que estos tuvieran terrenos suficientes para su sustento, aumento y pago del tributo. Las tierras de «demasía» o las «sobras» de indios regresarían al poder de la corona, por lo que se denominarían «realengas» y se podrían vender de acuerdo al interés y a las necesidades del rey. Además de cobrar por las ventas, la Real Hacienda ingresaría

2 La bibliografía sobre las composiciones en la región andina es extensa. Véase un resumen en Glave-Remy, 1983. 
por la medición y por el derecho al nuevo título que reemplazaría a los instrumentos que acreditaban alguna forma de propiedad.

Cuando en 1593 se puso en marcha la visita de composición de tierras, la real cédula de 1591 cobró un vigor no solo ejecutivo sino también doctrinal: el rey era el propietario de las tierras. Así, todo el peso de la conquista se cernía sobre las vidas y los intereses de los grupos indios: no eran ellos los dueños de las tierras a las que dedicaban y de las que provenían sus vidas. Pero la opresión ideológica no era lo más serio. Lo primordial entonces era que no perdieran más recursos. Además, si acaso pagar por sus propias tierras en ocasiones no resultase suficiente, también se adosó a la comisión de composiciones una orden que dispuso que los indios dieran un quinto más de las tasas de sus tributos cada año. La coyuntura de fin de siglo no era la mejor para las condiciones de reproducción de los naturales del reino.

La salida de los comisionados implicó una suerte de nueva «visita general» de los indios, de una envergadura comparable a la que se había desarrollado en 1572, pues la cédula señalaba que se compondrían las tierras que quedaran luego de que aquellos confirmasen o diesen las extensiones necesarias para el sustento de los indios. Es decir, había que evaluar el número y las capacidades de las comunidades y los pueblos para dotarlos de lo que se considerase suficiente para la reproducción y el pago de las tasas. Luego se procedería a la parte negociable, pero lo anterior no era desdeñable en cuanto a las dudas que tal trato pudiera desatar. Por eso, en noviembre de ese año de 1593, el virrey mandó que se formase una junta para reunirse con él cada miércoles para solventar las dudas. La conformaron, además del marqués, su asesor, el licenciado Rengifo - cuya trayectoria de acaparador de tierras lo hacía el menos indicado para el efecto-,${ }^{3}$ el abogado de los indios, doctor Alberto de Acuña, el veterano secretario de la gobernación, Álvaro Ruiz de Navamuel, el doctor Molina, canónigo de la catedral, y el franciscano fray Alonso de Valdivieso. Antes de analizar los pareceres respecto a la obra de los primeros visitadores y el panorama que encontraron, veamos las opiniones de dos de ellos, los primeros en salir, cuando empezaron su comisión. ${ }^{4}$

El obispo electo de Quito, Luis López, comisionado para la venta y composición de la región de Charcas, escribió para poner en conocimiento

3 Glave, 2009, 349 y ss.

4 Toda la información que se refiere a continuación proviene del Archivo General de Indias (AGI), Lima, 273, con anejos a cartas del virrey del Perú, marqués de Cañete. 
sus experiencias. ${ }^{5}$ Aunque en enero de 1593 estaba de asiento en Chuquisaca, andaba «de pueblo en pueblo» repartiendo tierras a los indios. Su peregrinar era tal que le escribió al virrey desde Guata diciendo que no podía responder al chasqui que llegase, llevando como llevaba prisa en avanzar por tantos lugares como era necesario. Consideraba que era preciso obligar a los corregidores de los partidos a que amojonaran las tierras que se habían repartido y señalado a los indios, para que se excusasen pleitos posteriores. López aseguraba que aquellos no lo querían hacer si no se les adjudicaba un particular salario, aunque la ordenanza de la visita lo establecía como su obligación. Por eso decía que se valía de gente experta que lo hacía por favor o por moderado salario. Además, denunciaba que si bien tenían prohibido llevar escribanos y hacer costas a los indios, lo cierto era que no lo cumplían. De hecho, había encontrado que en los pueblos llevaban dinero a cada indio por cada mandamiento, ni siquiera de sustancia sino sobre «cosas de aire», arrancándole peso y medio por la firma y el escribano, y les admitían peticiones por cualquier cosa en función del interés de los derechos del proceso. Por eso el obispo les decía a los indios que no «le hablaran por escrito», que le pidiesen y representasen de palabra sus necesidades, y que el escribano indio del cabildo elaborase una memoria de las tierras que demandaban. Lo que quería el visitador era que no gastaran ni un tomín en derechos y que si los hubiera, como en la elaboración de los títulos, se sacaran de los bienes de comunidad y no se echasen derramas entre ellos. Si no hubiera cajas comunales o no tuvieran bienes, López deseaba que se obtuviera el dinero de las ventas de tierras que se iban a hacer o de los salarios que se ahorraban por la rapidez de las gestiones, una de sus preocupaciones.

Los años previos y ese mismo eran de mucha esterilidad en una tierra áspera y fragosa, donde la mayor parte de los sembríos era de temporal y sujeto a los fríos, granizo y falta de agua. Los repartimientos estaban despoblados y era necesario que la gente volviese a sus tierras y reconociese a sus señores o jefes naturales. Solo se podría lograr ese objetivo con el manejo adecuado de la distribución de las tierras. Justificaba así que se vendiesen, pues López pensaba que esa era la manera de que no tuvieran donde esconderse. Descubría que los indios presentaban quejas infundadas que no había que atender, pues muchas veces eran visitados en sus lugares

5 AGI, Lima, 273, Informe de fray Luis López sobre su comisión para la venta y composición de tierras, 1593. 
de origen mientras se encontraban escondidos en otros pagando tributo, y que cuanto les pedían a sus caciques era que los dejasen en su «libertad».

López compartía la idea de que los «procuradores» inquietaban a los indios por el interés por los pleitos. No debía ser blando con los quejosos ni aceptar que se vendiesen tierras entre ellos, mandando regresar a los indios a sus pueblos e impidiendo que viviesen en otros, pero eso sí, dando siempre lo suficiente y más para que alcanzase y que se reprodujeran con holgura.

Brindaba el obispo más justificación a las composiciones y ventas, ya que estimaba que así se evitarían los infinitos pleitos que daban ocasión a los abusos de los caciques, especialmente que vendieran las tierras como quisiesen, haciéndose señores de ellas. Se debía dar orden de privación de cacicazgo a quien aceptase tener indios forasteros — que López llamaba extranjeros - trabajando las tierras de los caciques, y mandarse que todos regresasen a sus pueblos y que las tierras se vendiesen. Como se ve, la pieza clave era el poder de las autoridades étnicas para disponer de los bienes. Contra ellos se dirigía en buena medida la idea de la composición.

Por el lado de los nuevos hacendados, esta era desde luego la oportunidad de adquirir seguridad en sus labranzas. En los pueblos, mientras se hacían las visitas a las tierras de los indios, los chacareros iban dando sus títulos para que el visitador los viera. Algo ingenuo, López se sorprendía de que habiendo tanta esterilidad se fueran sacando dineros que no venían mal a las necesidades del rey. Las cosas quedarían claras para todos: no habría pleitos, los pueblos se verían colmados, los indios no experimentarían carencias, ni tendrían sus caciques oportunidad de abusar de ellos ni de tener recursos de los que disponer al margen del control fiscal de la tierra. Finalmente, los hacendados trabajarían con seguridad en lo que cabalmente detentaban por derecho. Nada de esto prosperó, puesto que todo fue abrir nuevas puertas a los tratos y a las contradicciones, al despojo de los más débiles, y a la ambición de los más fuertes. La hacienda real vería en ello nuevas oportunidades de hacerse con los siempre exhaustos recursos de que disponía para crecientes gastos.

Si bien la visita compartía algunas ideas con la general de la década de 1570, el visitador López no desaprovechó la oportunidad de hacer una severa crítica a lo que se había hecho entonces por orden del virrey Toledo. Aquella había fallado y esta era la oportunidad de remediarlo y de hacer efectiva una reducción general del reino. Afirmaba López que donde había dos pueblos podían formarse tres, y denunciaba que se habían repartido a 
los indios las tierras más estériles y de menos provecho, para ganar las mejores para los españoles. En consecuencia, tenían que ir lejos a sus chácaras, dejando las reducciones despobladas «porque ellos han de estar donde tienen sus chácaras aunque se hunda el mundo». Si bien los indios habían sido establecidos cerca del camino real para que tuvieran más trato con españoles, lo cierto es que esto se había traducido en mayores vejaciones. Para López, esta nueva visita ofrecía la oportunidad de cambiar las tasas en virtud de las existencias de efectivos indios, pues había habido muchas epidemias.

También contamos con los comentarios de octubre de 1593 de Alonso Maldonado de Torres, comisario para la visita de los valles del sur y el Cuzco. ${ }^{6}$ El visitador se encontraba en Cañete, villa a la que consideraba pobre, y estimaba que podría conseguirse mayor cantidad de dinero por composición en los valles que seguían hasta Arequipa, ya que los vecinos fundadores, que habían recibido tierras relativamente pobres, se habían compuesto por unos miles de pesos a plazos. El visitador no pensaba quedarse en los valles aledaños - que eran de indios- donde había proveído lo necesario, salvo para el de Pachacamac, que solicitaba que lo vieran desde Lima. Maldonado veía «trabajosísimos» los negocios de los naturales, de ahí que los dejará encargados a los corregidores pues, de lo contrario, pasaría la vida con ellos. Además, entendía que si delegaba el asunto acabaría costando más de lo que se obtendría. En el valle de Mala, que resultaba de lo mejor según Maldonado, se había metido un Alexo González Gallego con un hijo suyo y más de 2.000 cabezas de vacuno, desbaratándolo todo y dejando en la miseria a los indios. El visitador entendía que se le debía sacar de allí, ya que luego del reparto entre los indios quedaba buena tierra para vender. Es curioso que demostrase poco interés en el propio valle de Cañete, aunque ponderaba las tierras que se regaban con la acequia imperial, la cual se debía reparar. Maldonado manifestaba mucha expectativa con lo que vería en Mora, Chilca y de allí adelante. Había, según su parecer, muchas tierras pequeñas de españoles pobres e indios que las habían comprado de otros y de caciques, a los que se les debía aceptar algún pago por ellas, aunque la plata sería tan poca que mostraba desapego a la gestión. Sin embargo, reconocía que el quinto de los indios se estaba entablando bien, y estimaba que los valles de Mala, Chilca y Coayllo lo dor, 1593.

6 AGI, Lima, 273, Carta de Alonso Maldonado de Torres sobre su comisión de visita- 
pagarían muy descansadamente, sobre todo sacando el ganado al que hacía referencia más arriba. Lo mismo refería de los de Pachacamac, Chincha y Lunaguana, que también tenían buena disposición. En Cañete, en cambio, donde los indios no poseían bienes comunales, se les debería dar para cumplir con su contribución.

Estos comentarios revelan un panorama de lo que encontraron y de cómo lo enfrentaron los primeros visitadores. Asimismo, muestran sus opiniones, su forma de ver el negocio que traían entre manos, y las dificultades y las características de lo que tuvieron que enfrentar. Maldonado de Torres continuó la visita y fue uno de los ministros coloniales más relevantes de fin del siglo XVI, al punto de ser ascendido al propio Consejo de Indias. López fue separado de su cargo y volvió a su quehacer pastoral sin que se hicieran críticas personales a su trabajo, aunque despertó las más serias dudas que vinieron a solventar algunos pareceres de los que luego daremos cuenta. La visita continuó avanzando, sin embargo, ya evaluadas las dudas.

\section{Los pareceres expuestos a la junta sobre las dudas de la composición}

El inicio de las composiciones trajo de inmediato una polémica referida fundamentalmente a los derechos de los indios. En este marco, el virrey planteó unos puntos para que algunas personas dieran su parecer. Uno de ellos fue el abogado de los indios, Alberto de Acuña. Este hombre, que llegaría a ser uno de los más influyentes oidores de la audiencia limeña del siglo XVII, empezó su carrera pública por nombramiento del conde del Villar en la residencia de los virreyes Toledo y Martín Enríquez. Había pasado al Perú como asesor del conde y sirvió exclusivamente en las residencias por tres años. Durante ese lapso, cuidó de estudiar las leyes y de entender las cosas del reino, sacando algunas advertencias para el cuidado y aumento de la hacienda real, las que transmitió al virrey. Al marcharse su patrocinador, pidió que se le hiciese alguna merced por sus servicios y, mientras tanto, se entretuvo leyendo la cátedra de vísperas de cánones en la universidad y defendiendo a los indios del reino como abogado de naturales, cargo para el cual lo había nombrado Villar y reafirmado Cañete. En esa condición fue incluido en la referida junta de las visitas de las tierras.

El virrey, de acuerdo a la cédula que declaraba que las tierras eran de propiedad real, ordenó que quienes no las poseyesen con justos títulos las 
devolviesen y restituyeran, para lo cual dio una provisión el 17 de noviembre de 1593. La voluntad real expresaba que esas composiciones se harían mientras que a los indios se les repartirían las tierras que «buenamente hubieren menester para que hagan sus sementeras y crianzas, confirmándoles en lo que tienen de presente y dándoles de nuevo lo que les fuere necesario». Solo luego de este reparto, por hacer bien a sus vasallos, podrían venderse o componerse las restantes. Si bien el virrey manifestó haber nombrado personas de satisfacción para que ejecutasen la comisión, también dispuso la formación de una junta — de la que participó Acuña— para que en ella se aclararan las dudas que se presentasen. Las que se suscitaron fueron las siguientes: ${ }^{7}$

1. Si debían dejarse en poder de los indios y de sus caciques las tierras que poseían sin justo título, incluso si fueran muchas más de las que necesitasen, o si, por el contrario, debían quitárseles dejándoles solo las que se estimasen necesarias para su sustento y las que poseyeran con justo título. Asimismo, se debía precisar si podría haber con ellos composición como con los españoles.

2. En el caso de reconocerles a los indios la posibilidad de componerse, se planteaba el interrogante de qué derecho se tendría por suficiente para hacerlo y cuál no, teniendo presente que no poseían escrituras ni mercedes particulares que se les hubieran entregado. Se debía determinar también qué cantidad se habría de componer, presuponiendo que se mandara que a todos se les diesen las tierras necesarias.

3. En caso de que no hubiera comisión para quitarles las tierras, qué orden se podría dar para que fuesen restituidos en lo que se les hubiera tomado y vendido, satisfaciendo el precio a los que las habían comprado.

4. Si habría obligación de devolverles las tierras a los indios queriéndose componer por ellas, y si parecería bien hacerlo aunque ellos no lo pidiesen. Se dudaba también si convendría sacar el dinero de los bienes de comunidad aunque las tierras fueran de particulares.

5. Si había obligación de dejar a cada pueblo de indios alguna cantidad de tierra para dehesa y pasto en que pudieran tener sus crianzas fuera del pasto común, donde los españoles no pudieran meter sus ganados.

7 Estas cuestiones aparecen en un escrito titulado «Los puntos sobre los que han de dar parecer las personas a quien su señoría el señor marqués de Cañete visorrey ha mandado juntar para lo tocante a la visita de las tierras son los siguientes», 1593, AGI, Lima, 132. 
6. Si los españoles estaban obligados a composición aun teniendo títulos buenos.

7. Cuál era un buen título en ese caso.

Habiendo visto estos puntos sobre la interpretación y la ejecución de las cédulas, Alberto de Acuña pasó a dar su parecer. ${ }^{8}$ Reconocía que no era el espíritu de las cédulas que se quitasen las tierras a los indios, ya que todas, incluso aquellas que tenían y poseían aunque no las cultivasen, eran suyas y no necesitaban ser justificadas con títulos válidos: no las tenían por merced ninguna. Las tierras de los indios no estaban sujetas a limitación alguna y, por lo tanto, no se les podían quitar.

Hubo dos cédulas para la ejecución de las composiciones, una primera de gran rigor y una segunda que lo moderaba, pero la severidad se enfocaba en las posesiones de los españoles y para nada en las de los indios. La composición se mandó hacer con la finalidad de que los españoles que poseían tierras sin justo título -incluyendo las mercedes otorgadas por quienes no tenía potestad para darla — las restituyeran al rey. Aquellas que se quitasen a los españoles debían repartirse para ejidos y propios de los pueblos, así como a los indios que las necesitasen buenamente. Solo entonces se compondría lo sobrante. Así, a quienes se quitarían tierras sería a los españoles y de ninguna manera a los indios. En lo que se refiere a los terrenos baldíos, no se denominaría así a los de los indios, sino a aquellos que, siendo sobrantes sin posesión, nunca habían sido repartidos o concedidos.

Acuña, por su parte, afirmaba que el emperador había mandado «que todas las cosas de la tierra se conservaran en el estado que tenían cuando entraron en ella los españoles», y recordaba que cuando las autoridades habían hecho mercedes de algunos pedazos bastó la mera contradicción de los indios para que no tuvieran validez. Todo esto, denunciaba, no se había cumplido y lo mismo ocurría con el programa de reducciones. Aseguraba que estas en principio no debían afectar a las tierras que los indios tenían, pues si bien Toledo había repartido nuevos terrenos a los naturales que mudó a nuevos pueblos, no les quitó los que antes poseían sino que se los adjudicó, dejó o vendió por suyos. Acuña sostenía no ser cierto que los indios no pudieran tener más tierras de las necesarias, pues resultaban tan capaces como los españoles para poseerlas. Recurría, para avalar esta afirmación, a la junta de cardenales que al efecto había mandado formar el pontífice Paulo III.

8 AGI, Lima, 132, Instrucciones y parecer de Alberto de Acuña, 1593. 
Había unos supuestos jurídicos y regalistas que eran imbatibles respecto a los derechos y al papel de la sociedad nativa. Decía Acuña que:

hace mucho por esta parte que sabe el rey nuestro señor que la riqueza de esta tierra de que participan y se sustentan todas las más de la cristiandad, procede de solos los indios, los cuales la dan toda sin reservar para si cosa alguna y que son los pies y estribos de esta república que la tienen sobre sí y la sustentan y que ella va creciendo y ellos disminuyéndose y enflaqueciéndose de manera que han menester ayuda y no desayuda.

Luego mencionaba la plata de residuos de tasas que les había aplicado Toledo, ya que la presión sobre los recursos de los indios era tremenda. Hacía cuatro años, en 1590, que el rey había mandado llevar a España lo que entraba en las cajas comunales, como el rubro de residuos y buenos efectos. Así, el ejemplo que dio el propio virrey Toledo, que tomó de allí lo que consideró que se le debía por sus viáticos del tiempo de la visita que ejecutó personalmente, fue continuado por el mismísimo rey. Los fondos eran un «residuo» luego de los pagos del derecho del encomendero, del salario del cura, del cacique y otros. Fueron pensados como una «ayuda», al ver lo crecido que era el monto de trabajo y riqueza que debían dar por tributo. Pero ese recurso, que procedía de la producción colectiva de la comunidad, de sus bienes y recursos, terminaba siendo pasto del que comía cualquier necesidad fiscal o de la más alta autoridad virreinal. Encima, el año siguiente al préstamo real — que nunca se terminaba pagando- le «sirvieron» los indios con casi todo lo que les quedaba de comunidad.

Las evidencias muestran que los curacas se tomaron muy en serio esos pedidos de servicio gracioso, para apuntarlos en los méritos que luego presentaban como prueba de fidelidad. Echaron mano, sin embargo, de los bienes de comunidad que eran también resultado del trabajo colectivo y del consumo de sus recursos, incluso de las tierras que vendían o ponían a censo. Por ejemplo, cuando el comisario de Huamanga informaba sobre lo que iba recolectando, figuraban distritos donde solo hicieron donaciones los indios, como los de Chocorvos y los de Zangaro. No siempre fueron recursos comunales los que salieron por donativo; por ejemplo, Juan Aymoro, cacique de Yamparaes, Yotala y Quila Quila, se encargó de dar cuenta de que tan pronto recibió del administrador de la caja de censos su salario como cacique, que ascendía a 750 pesos ensayados, los entregó de inmediato como servicio gracioso. ${ }^{9}$ Los indios se habían mostrado muy genero-

9 Sobre Aymoro, ver AGI, Charcas, 44. 
sos y leales ante el pedido que formulara la cédula real y el apremio del que hicieron gala los recaudadores.

Además del retiro de los residuos de las cajas, del donativo, de las cédulas de composición y de las cargas y trabajos a los que estaban obligados, se dispuso que los indios pagasen el quinto de más en sus tributos, como parte de las medidas de emergencia para solventar los gastos de guerra del rey. Ese quinto de más resultaba difícil de pagar, así que «no es verosímil» —decía Acuña— que se mandase quitarles tierra alguna a los indios. Ellos no tenían otra cosa que sus terrenos y eran precisamente ellos su «áncora y estribo» para sustentarse y pagar los tributos. En el supuesto de lo que no se podía hacer, Acuña hacía una terrible predicción: «no es mucho que les sobre un pedazo que arrendar y dejar a sus hijos o a su ánima y si se les quitase sería acabarlos e imposibilitarlos de que ellos ni sus descendientes no puedan jamás tener aliento ni descanso». No podía el monarca católico patrocinar tremenda miseria, mayor que todas las muchas que entonces tenían juntas, «que son tantas y tan grandes como es notorio».

Decía el abogado que no se debía aludir a que los indios tuvieran muchas tierras, como en efecto en algunos casos ocurría. El rey, recordaba Acuña, tenía información sobre esto, pues en su consejo contaba con Pedro Gutiérrez Flores, que había manejado el asunto. Como no decía nada expreso en las cédulas sobre esto, afirmaba el abogado, no se podía hacer lo que no estaba mandado ni suponer por una conjetura incierta, como fue el proceder del inicio de las composiciones según se había visto en los informes y opiniones de López y Maldonado.

Según Acuña, se podía aducir que convenía que se vendiesen las tierras que poseían en demasía los indios para que se labrasen y se sustentase la tierra, pero reconocía que eso no era así. Los indios ya las arrendaban, o lo podían hacer, dándolas baratas a gente pobre que las beneficiaba abaratando las mercancías agrarias y tratando bien a los indios para que los ayudasen al beneficio. No como había ocurrido cuando se habían vendido las sobrantes a personas poderosas que encarecían las cosas y sus mayordomos maltrataban a los indios. Luego, aseguraba, venía el español que había comprado la tierra a pedir al mismo indio que la vendió para mitayo, quitándole así su tierra y su libertad.

En una carta de 12 de abril de 1594 Acuña relataba que habían ido enmendando las instrucciones primeras, pero que en Charcas el obispo López y sus subdelegados habían sido los primeros en hacer la visita realizando una interpretación muy rigurosa de su comisión. Por ejemplo, no 
aceptaron que los indios se compusieran por tierras que se les quitaban, haciéndolos inferiores a los españoles. En concreto, habían procedido de tal forma que se acumulaban las denuncias: que les quitaron tierras suyas desde sus antepasados, que se las trocaron por otras inferiores, que los despojaron de las fértiles y les dieron pedregales, que los dejaban sin agua, que vendieron las tierras a gentes poderosas de la provincia y a los indios los constriñeron a las mínimas sin dejarles lo que la visita general les había señalado por decir que habían muerto muchos. Luego, denunciaba Acuña, los repartían para que beneficiasen sus propias tierras haciéndolos más esclavos, como más adelante lo denunciarían los propios indios.

Sobre los justos títulos de los naturales también hacía una referencia el parecer de Acuña. No cuestionaba el derecho del príncipe, pero sí justificaba la posesión por herencia de padres y abuelos, y la posesión libre de buena fe por varias décadas desde la conquista. Si no por posesión antigua, también avalaba la posesión el reparto en la visita general autorizada por leyes justas. No era necesario nada más para que no se cuestionase su posesión. Incluso, cuando no fueran suficientes los justificados argumentos señalados —o no fuera claro todo esto—, se les debía admitir una moderada composición si lo deseaban por no ser menos que los españoles. De este modo, el rey «los aventaja y hace mejores que ellos, y es justo que lo sean».

En resumen, Acuña solicitaba que no se siguiesen vendiendo las tierras de indios y que se restituyeran las que se habían enajenado sin esperar la consulta con el rey, a quien se remitirían las dudas y pareceres, suspendiendo las actuaciones en relación a los naturales. Asimismo, reclamaba que se restituyeran los terrenos tomados y se devolviera lo pagado por los interesados. Para Acuña, si los indios querían componer tierras se debía aceptar que lo hiciesen con las cajas de comunidad, salvo que fuesen de un particular. En este caso, se podría prestar de las cajas y arrendar la tierra para que se hiciera el pago del común y el indio se quedase con la tierra, sin que se entrometiese un español. Así quedarían libres de esa «polilla». Además, según Acuña convenía que se dejasen pastos o dehesas para que los naturales tuvieran sus ganados.

El entonces abogado de los indios elaboró también, paralelamente a su opinión sobre la composición, una corta pero fulminante oposición al pago del quinto recién impuesto, dando como justificación lo cargadas que estaban las comunidades de indios y repitiendo algunas causas del parecer anterior. En otra carta fechada en Lima el 20 de noviembre de 1593, Acuña se refirió también al servicio gracioso. Decía que los comisarios habían 
apretado más de la cuenta en el servicio de indios particulares y explicó que habían acudido a sus bienes comunales para hacer frente a dicha carga. Aseguraba el abogado que los indios habían otorgado todo lo de sus comunidades que eran poco beneficiosas para ellos, por ser «los cuchillos con los que son atacados por los corregidores que llevan lo que hay en ellas en sus tratos».

La visión general de la economía que tenía Acuña era muy pesimista, ya que consideraba que las cosas estaban más caras, mientras que el trabajo de la tierra era el mismo pero el fruto menor. En consecuencia, la familia india resultaba cada vez más pobre. Completó su parecer sobre tierras recalcando la importancia del regadío y solicitando que los terrenos de los indios se ubicaran en las cabeceras de agua para que no se la quitasen los españoles.

Aunque su nombre no figuró entre los convocados a la junta para solventar las dudas sobre la composición de las tierras, el deán de la catedral, el doctor Pedro Muñiz, también emitió su opinión acerca de este asunto. ${ }^{10}$ El deán era conocido por un parecer igualmente importante al que comentamos que estaba referido a la cédula que prohibía los servicios personales de los indios. Esta opinión había sido elaborada probablemente en 1603 a pedido del virrey Luis de Velasco. El testimonio de Muñiz se encontraba en el listado de los que se dieron por entonces, los más famosos de los cuales fueron el del franciscano Miguel de Aguia y el del jesuita Alonso Messía Venegas.

Muñiz había nacido en Baeza, Castilla, en 1545. Una vez ordenado sacerdote pasó al Perú junto con sus padres y su hermano Hernando, que habría de amasar una considerable fortuna. Se doctoró en San Marcos, universidad de la que llegaría a ser rector en más de una ocasión. Pasó a Cuzco en 1581, donde hizo una visita al valle de Collaguas, encontrando grandes abusos de los clérigos contra los indios. Allí realizó unas condenaciones que ascendieron a 6.000 pesos que restituyó a los naturales. Estuvo cerca del virrey conde del Villar, quien le permitió regresar a Lima y lo tuvo como su asesor eclesiástico hasta 1593, cuando se convirtió en deán de la catedral. Todos sus contemporáneos coincidían en su calidad académica y lo tenían por sabio, de ahí que su opinión fuera relevante para buena parte de la élite, desde el arzobispo Mogrovejo hasta el virrey Velasco. ${ }^{11}$

10 AGI, Patronato, 191, Parecer del deán Pedro Muñiz, 1593.

11 Fox, 1962, 63-88. 
Al igual que el abogado de los indios, este teólogo suscribió contundentemente que no existía mandato para quitarles tierras a los indios en virtud de las cédulas de la composición. Más bien todo lo contrario, ya que según Muñiz el rey pretendía favorecer a los naturales y preferirlos en todo a los españoles. El deán se cuidaba de empezar su parecer con un «presupongo que el rey nuestro señor no endereza estas cédulas contra los indios, antes en ellas les hace merced muy particular». Así, como podemos advertir fácilmente, lo que estaba en juego era la licitud de quitar tierras a los naturales, como lo habían puesto en práctica los primeros visitadores, dos de ellos connotados miembros de la jerarquía religiosa como el padre maestro fray Domingo de Valderrama y el electo obispo de Quito Luis López. Esos visitadores habían actuado contra los indios y esa, como puntualizaba Muñiz, no era la voluntad real. Claro que no aparecían en este testimonio casos muy gruesos, puesto que el deán limeño se contentó con señalar episodios menudos, como dotes de indias, tierras privadas de indios, e incluso «haciendas» que fueron compuestas con estos naturales cuando por derecho les correspondían. El tema de los «justos títulos», que atañía a la manera cómo se trataba la propiedad de las tierras por parte de los españoles, era un telón de fondo. Las cédulas se cuidaron en señalar que los títulos válidos eran aquellos que los soberanos habían dado o también aquellos otorgados por quienes tenían un mandato legítimo para hacerlo. Por ejemplo, las tierras que los primeros conquistadores habían concedido. Pero con los indios era otra la materia, puesto que los reyes de España sucedían a los señores del reino, cuyo patrimonio había revertido a la corona. De tal forma que las posesiones de los caciques y de los señores naturales de los indios - heredadas de sus antepasados- como también las que los indios tenían particularmente o en común desde tiempos remotos, no podían enajenarse aunque fueran más de las que necesitaran.

Muñiz se refirió a los indios de dos pueblos del entorno del Cuzco, muy apetecidos por los vecinos de la ciudad por su buen clima y productividad: Maras y Quispicanche. Ambos tenían enormes tierras de comunidad. Sabemos que efectivamente había allí una frondosa sociedad noble, que había entrado con razón o sin ella en tierras que habían sido de culto y de los incas, heredándolas de facto. Fue a propósito de esas tierras y de sus ventas que muchos españoles adquirieron sus primeras propiedades en el campo, comprándolas a los caciques o a los nobles. Cuando no pudieron, se ingeniaron unas compañías con los caciques para que se pusieran en producción tierras que los indios no usaban y obtener de ellas unas rentas que 
de otra forma no podrían alcanzar, tanto por falta de tierra como también por falta de trabajo. Estas compañías se justificaban porque eran una forma de ayudar a la paga de tributos. Hemos llamado a ese periodo el de la «hacienda antigua». Muñiz veía en ello un beneficio para los indios a los que denominaba ricos. No evaluaba la tendencia que ello implicaba a que pasaran - como ocurrió luego- las tierras a manos de los no indios. Pero lo que sí era cierto era que quienes controlaban los recursos básicos de la producción eran los indios. Las composiciones, al abrir las puertas a otras formas de acceder a la tierra saltando esos derechos, fueron un abuso legal que estos pareceres que comentamos se encargaron de advertir.

De hecho, los indios de algunas zonas podían ser tenidos por ricos cuando la tierra ya era un codiciado bien de mercado, como el caso de caciques que, teniendo sus pueblos muy mermados, habían entrado en propiedad de terrenos de ayllus desaparecidos y los manejaban como bien particular. Esa era por lo menos la acusación y la justificación de su posible enajenación por vía de composición. Pero, sin considerar que estos jefes étnicos siempre habían tenido que cumplir con formas de redistribución que limitaban culturalmente sus acumulaciones personales, Muñiz decía que en estos casos se debía establecer un reclamo fiscal y un juicio legal que precisara los derechos justos a esos bienes. Acertadamente recordaba que este frente de lucha por la tierra ya se había evaluado en la visita general toledana — advirtiendo el poder de los caciques- y que se habían hecho repartos que tomaban en cuenta todo esto, como lo sabía por ejemplo fray Pedro Gutiérrez, que había estado en la visita y entonces era miembro del consejo.

Concretamente Muñiz señalaba que la visita de fray Domingo Valderrama había arrojado una gran cantidad de tierras que se quitaron a los indios, a quienes pedía que se las restituyeran. Proponía hacerlo mediante el reclamo del protector de naturales y que los tribunales, a vista de los verdaderos poderes de la comisión del visitador, fallasen justamente dando a los indios lo que era suyo.

La resolución del virrey de 4 de enero de 1594 respecto de las tierras de los indios aceptaba, en general, los pedidos de Acuña y Muñiz. Ordenaba que no se quitasen las tierras, que si hubiera algunas poseídas con poca justificación se compusiesen — si así lo querían—, y que por otras que hubieran compuesto los españoles los indios pudieran ofrecer el tanto y quedárselas. A pesar de la creciente presión sobre los terrenos indígenas, estos debates — que tenían detrás una lucha legal constante de los propios 
indios y sus jefaturas - permitieron una legislación protectora que impidió la pérdida mayoritaria de los recursos naturales que manejaban, con los cuales se reproducían y cumplían con las imposiciones coloniales. Pero siempre quedó abierta la puerta para que el proceso de apropiación de tierras por parte de los vecinos y los nuevos empresarios continuara: la norma estableció que si los indios tuvieran propiedades en guaicos - quebradas- donde se pudiesen esconder se les cambiaran por otras cerca de sus pueblos. Además, se dispuso que se juntasen en sus pueblos y que se les repartiese - si resultaba conveniente - las que estaban cercanas. Esa ambivalencia, acompañada de los juegos de intereses en el terreno concreto del mercado de tierras, permitió que pronto se propusieran nuevas medidas para vender terrenos sobrantes o mal compuestos. Fue, en definitiva, un espacio abierto para las elucubraciones arbitristas.

\section{El arbitrio sobre la nueva venta de las tierras}

En este contexto, Pedro Ugarte de la Hermosa presentó un largo papel sobre las tierras datado en $1622 .{ }^{12}$ Se trataba de un arbitrio como los que entonces comenzaron a proliferar, que mereció la realización de una encuesta en la que la opinión de Francisco de Alfaro destacó por su oposición frontal. Paradójicamente, la oposición de Alfaro permitió a Pedro de Vivanco perfilar una alternativa. El nuevo arbitrio subrayaba el fraude en las composiciones anteriores, pero marginaba y ocultaba el tema de las tierras de las que se despojaba a los indígenas en esa misma coyuntura, como se podía objetar en la lectura del memorial de Ugarte. En estos arbitrios se ofrecían terrenos que quedaban vacíos — «vacos»— por la disminución de indios, los que se aumentarían reubicando a las poblaciones en nuevas reducciones. Como si todos hubieran quedado amnésicos, el debate sobre las tierras de los naturales y el derecho a ellas, que hacía poco más de un par de décadas que se había desatado, quedaba en el olvido. Para afianzar la posibilidad de seguir tomando tierras de los indios, estos memoriales volvían al tema de la reducción, como si se retrotayera la historia a la época del virrey Toledo.

Gracias a un artículo de Antonio Dougnac que trabajó los escritos de Francisco Ugarte de la Hermosa y Salcedo, hijo de Pedro Ugarte de la

12 AGI, Indiferente, 2690, Papel de Pedro Ugarte de la Hermosa, 1622. 
Hermosa, nuestro arbitrista, sabemos de la estirpe de escritores que estableció este militar. ${ }^{13}$ Pedro pasó al Perú en la armada de 1592, y en 1604 obtuvo una plaza de gentilhombre. Aunque era un individuo de armas también fue de «pluma fácil», al decir de Dougnac, virtud o práctica que entrenaría como escribano de un galeón que se hundió y luego como escribano y secretario del gobierno de Chile que ejerció Lope de Ulloa y Lemos. Pero su perfil más preciso lo ubicó en el campo militar, por lo que obtuvo mercedes de tierras en Chile. Luego de sus años en el sur del virreinato volvió al Perú y a España, para finalmente terminar en Lima como procurador general de la compañía de gentiles hombres de lanzas y arcabuces. Dice Dougnac que escribió un compendio de historia de Chile que se ha perdido, y un memorial sobre la reducción de los indios. Su hijo se ordenó sacerdote y fue un connotado escritor que volvió sobre el tema de la reducción. Tenemos también la información de 1623 de los méritos del capitán Pedro Ugarte de la Hermosa que fue reproducida en 1648 por su hijo, el bachiller Francisco Ugarte de la Hermosa, que buscaba una canonjía. ${ }^{14}$ Pedro también presentó en 1632 una probanza de los méritos de su otro hijo, el alférez Antonio Ugarte, que sirvió y murió en Chile en la guerra contra los araucanos. En la probanza de 1623 para la información de méritos de Pedro depuso el contador Francisco López de Caravantes cuando tenía 52 años, un vínculo interesante para alguien que debía preciarse de conocer los problemas económicos del reino. Confirmó el contador que Luis de Velasco le dio una plaza de Lanza. No declaró, como otros, que Ugarte había estado en el alzamiento de los negros de Quillabamba, una de las razones por las que recibió la plaza. Era un hombre de armas, que enfrentó a los piratas y sirvió en Chile, aunque en diversos momentos también se decía conocedor de papeles. No consigna su arbitrio a pesar de que fue elevado en 1622, tal vez por la proximidad temporal entre su presentación y el levantamiento de la información, pero no deja de extrañar que siendo el arbitrismo un mecanismo para escalar socialmente, este militar no lo haya consignado en su relación de méritos.

El arbitrio de tierras que el capitán Pedro Ugarte de la Hermosa había remitido desde Lima el 10 de mayo de 1622 provocó una encuesta el 31 de marzo de 1627, que en 1628 dio lugar a cuatro respuestas que fueron objeto de un estudio pionero por parte de Fred Bronner. ${ }^{15}$ En ese debate se ins-

13 Dougnac Rodríguez, 2012, 29-55.

14 AGI, Lima, 242, n. ${ }^{\circ}$.

15 Bronner, 1981, 418 y ss. 
piró u obtuvo la información uno de los tramitadores de arbitrios de la época del conde-duque de Olivares, Pedro de Vivanco, que elaboró su propio arbitrio de tierras que Bronner comparó con el de Ugarte. Esta y otras propuestas han dado lugar a nuevos estudios sobre la situación de la política indiana en la época del conde de Chinchón, cuando se buscaba ampliar los ingresos reales topando con la compleja situación que se vivía en la economía y en la política del virreinato. ${ }^{16}$ Lo que aquí vamos a presentar es el debate interno que suscitó el arbitrio y la reedición de la lucha entre el interés de ampliar el sector de la nueva forma productiva de las haciendas agropecuarias y los indios que procuraban mantener sus recursos y reproducirse dentro de la sociedad colonial.

\section{Nuevos debates sobre el destino de los recursos económicos de los indios}

Pero frente a las pretensiones de abrir un debate que ya antes se había suscitado sobre el mismo tema, no todo era olvido en esa corte con ataque de amnesia. Hubo quienes respondieron a las inquietudes de la corona sobre seguir con el arbitrio de tierras y recapitularon con precisión la historia previa. Contamos con un informe de la Real Audiencia de Lima sobre las composiciones de tierras de 26 de mayo de 1629, que firmó entre otros nuestro conocido jurista Alberto de Acuña que ya era oidor. En él, los ministros hacían una breve historia de este mecanismo de cambio en la agricultura. La carta respondía al pedido de información que se mandó hacer en 1627 ante el arbitrio de Pedro Ugarte de la Hermosa para que se vendiesen las tierras que quedaban por la muerte de los indios. ${ }^{17}$ Los miembros de la audiencia se remontaron a cuando el virrey Toledo excluyó de las potestades de los cabildos el conceder mercedes de tierras como se habían efectuado en un principio. Por este motivo, aseguraban, se notó que muchos españoles entraron en tierras que no les correspondían por justo título y, a instancia del conde del Villar en 1589, se fraguó la cédula de las composiciones. Decían los oidores que estas visitas de la época del marqués de Cañete no fueron bien entendidas en sus facultades por los visita-

16 Nos referimos a los artículos de Amadori, 2008, 2012 y 2013.

17 AGI, Indiferente, 2690. Toda la información, con las respuestas de los consultados sobre el arbitrio, proviene de este legajo. 
dores que acabaron perjudicando a los indios. En este sentido, en su informe se insertaba copia de los capítulos de la respuesta de 1595 a una carta del marqués de Cañete de 1593: «preguntáis si se quitarán a los indios las tierras que tienen de más de las que han menester y lo que en esto parece responderos es que no solamente no se las quitareis sino que los favorezcáis y deis más tierras a los que no tuvieren cumplidamente las que hubieren menester».

Corregido el defecto, la visita dejó claro lo que eran tierras de indios y lo que eran tierras privadas, quedando ya muy pocas vacantes. Por eso, según los ministros, luego de la visita la expansión de las tierras de españoles se había producido con mala fe. El mecanismo había estado a cargo de los corregidores, que declaraban vacantes tierras de naturales sin que mediasen averiguaciones. Luego, dichas tierras podían pasar a poder de los españoles. No descuidaban señalar que los indios huidos no estaban muertos y que si se continuaba perjudicando sus bienes acabarían huyendo también los que se habían quedado. Ya aparecían en el discurso los yanaconas, que eran recibidos por los propietarios que los protegían dándoles un pedazo de tierras, pero todavía no se utilizaba el término hacendado.

Otros abusos ocurrían por no haberse dejado claro el tema de las sucesiones, de tal forma que los curas se encargan al morir los naturales de persuadirlos o simplemente de fraguar cesiones para formar capellanías de las que terminaban disfrutando ellos mismos. Para todo esto los ministros solicitaban que se dieran provisiones.

En Madrid ya estaba tomada la resolución de proceder a una nueva composición, porque era evidente que los propietarios se habían expandido en tierras que se llamaban «demasías». Sin embargo, se seguía diciendo que los terrenos de indios debían dejarse pendientes en vista de que continuaba la discusión sobre la necesidad de realizar una nueva reducción que era el otro debate paralelo, sobre el que desde luego hubo innumerables arbitrios. Estas advertencias acerca de la manera fraudulenta en que se avanzaba en la posesión de tierras en los pueblos y valles sirvieron como acicate a las autoridades de Madrid para considerar el tema de la nueva composición y solicitar informes a las autoridades del virreinato. La carta de la audiencia fue una de las tantas respuestas a este pedio.

Este fue un momento crucial en la historia agraria, una coyuntura de expansión de las haciendas. Sin embargo, el arbitrio sobre composiciones que condujo a Lima el contador Hernando de Valencia no tuvo efecto, ya que Chinchón consideró que había que hacer la reducción antes de realizar 
cualquier innovación respecto de las tierras. ${ }^{18}$ En 1631 el virrey recibió una cédula para proceder a la composición, pero fue acompañada de una cantidad de propuestas que pretendían obtener beneficios de cuanto negocio pudiera imaginarse, desde el descubrimiento de tesoros hasta la venta del más insignificante oficio. ${ }^{19}$ Pero no era ese el motor de la apropiación de las tierras ni del desarrollo del mercado. La concentración de la propiedad y el proceso que estaba en camino tenía que ver con las iniciativas desde el mercado y la sociedad, más que con la legislación y los intereses de la corona.

En esta coyuntura, la intervención de Francisco de Alfaro fue lo más saltante para entender la relación entre el universo indígena y las tendencias de desarrollo de la república de españoles. Como señalamos, Pedro Ugarte de la Hermosa escribió un memorial que contenía un arbitrio en el que se refería a la gran cantidad de ingresos que la caja real podría obtener de las tierras que hubieran «vacado» por muerte de los indios. En 1627, el Consejo de Indias solicitó el parecer de las principales autoridades del Perú. Las respuestas están fechadas en 1628 y uno de los que respondió fue Francisco de Alfaro. ${ }^{20} \mathrm{El}$ documento es uno de los alegatos indigenistas más importantes de los funcionarios que defendían la separación de repúblicas:

Afirmo que de las cosas que más perjudiciales han sido en este reino son las que han llamado composiciones y no quiero decir que el año 93 cuando se trató este punto no había muchas tierras que poder vender pero digo hablando del partido de la Audiencia de los Charcas que se ejecutó muy contra lo que V.M. mandó y acuérdome que siendo Fiscal della en una carta que a V.M. escribí cité algunos repartimientos donde había V.M. perdido de tributos hasta entonces más de lo que habían valido las composiciones y desde aquel tiempo aca claro está que sin comparación será mayor el daño.

La estafa a las rentas del rey se había perpetrado en las primeras composiciones, los indios habían dejado de pagar tributos a causa de las composiciones, y, lejos de ganar con las ventas de las tierras, se había perdido y además perjudicado a la sociedad india.

Pese a que se refería a una vieja historia de 1593 para abordar el tema del arbitrio de 1627, Alfaro continuó retrocediendo aun más en el tiempo. Opinaba que luego de la visita de Toledo de 1572 no tuvieron los cabildos más autoridad para dar tierras a los vecinos por haberle quedado prohibi-

18 Amadori, 2013.

19 Bronner, 1977, 34-78.

20 AGI, Indiferente, 2690, Parecer del oidor Francisco de Alfaro sobre el arbitrio de venta de tierras, 1628 . 
do. Sin embargo, las autoridades de las ciudades continuarion siguiendo el orden legal antiguo. Según Alfaro, esas posesiones eran fraudulentas aunque fueran avaladas en 1593. Luego de las composiciones de finales del siglo XVI, los virreyes tampoco pudieron dar tierras por ningún título, habida cuenta de que justamente las composiciones partían del principio de que las propiedades eran del rey. Los virreyes, sin embargo, desde el tiempo del marqués de Cañete habían hecho dos tipos de composiciones: unas a pedimento de los particulares directamente, y otras despachando comisionados a los diferentes partidos, que compusieron nuevas tierras con quienes las poseían de hecho o simplemente las vendieron de nuevo.

La historia agraria andina de principios del siglo XVII muestra que efectivamente la denuncia de Alfaro era cierta. Como bien dice el funcionario indigenista, las peticiones particulares se hacían al cabo de cualquier «entrada» a las tierras a través de los indios, incluso particulares, que vendían terrenos que no podían enajenar puesto que no eran suyos. Otras veces eran los propios corregidores los que obtenían provisiones «que se tenían por ordinarias», para hacer informaciones respecto a las tierras y dar sus pareceres acerca de si eran susceptibles de componerse «sin perjudicar a los indios». Desde luego era la norma en las opiniones de los corregidores apoyar la ampliación de las posesiones españolas en territorios de los indios. Por muy poco dinero, además, se sancionaban expansiones considerables de terrenos.

Luego, ante cualquier denuncia de los indios, siempre era imposible la «restitución», pues los españoles alegaban haber hecho mejoras que las más de las veces, como subrayaba Alfaro, valían más de lo que se había pagado por las tierras o lo que se suponía valían de acuerdo a tasación. Así, los tribunales se atestaron de largos pleitos donde «estas composiciones que no lo son» se validaban y afirmaban.

Conocedor de la sociedad india y de los procesos de enfrentamiento a las reducciones, Alfaro pasaba a mostrar cómo incluso si la burocrcia procedía correctamente el mal que se hacía resultaba irreversible:

Pero demos que en algún caso no fue esto así y que el pleito se facilitó y se despachó muy como convenía y era justo, no basta esto porque aquella primera acción de quitar la tierra a los indios fue bastante para que se fuesen de su reducción para poder sembrar dos granos de maíz o donde les diesen por su trabajo. Con poca dilación que el pleito tenga, los indios se quedan donde se fueron sino es que se murieron dentro de poco tiempo y con esto queda el daño irreparable y los pueblos se discipan como hoy se ve y por vista de ojos pudiera yo decir mucho. 
El argumento era más contundente entonces: las fugas, los rezagos de los tributos y la crisis de población que se comenzaba a vivir tenían su causa última en las composiciones. Los indios buscaban otros terrenos fuera de los pueblos, ya fueran independientes o haciendas que se expandían, por cierto, a costa de las tierras de otros indios. El problema de los retrasos en los pagos de los tributos era la evidencia de este proceso, pero esa circunstancia solía ser presentada también de forma interesada por los propios causantes del daño, que agredían a la sociedad india a la que se debía proteger. Alfaro arguía al respecto:

\begin{abstract}
Veo también que para que las tasas de V.M. no se enteren y cobren, la excusa es indios muertos. Para dar tierras a los españoles la color es indios muertos. Para que los pueblos estén llenos de españoles contra cédulas Reales y que estén tomadas las casas sin pagarles siquiera alquiler, la color es indios muertos y para que haya tierras los huídos cuentan por muertos y el huirse y mudar temple y el descontento quizá ha hecho morir a muchos. Pero cuando se trata de excusar indios de mita, de trajines, de obrajes y de otros servicios personales, entonces no hay indios muertos sino idólatras que huyen de la doctrina, que se están viviendo en los huaycos y otras cosas de que sabe Dios la verdad y cada cual habla como le importa.
\end{abstract}

Así quedaban al descubierto los discursos interesados de los agentes que presionaban sobre los recursos de la sociedad india. Alfaro lo afirmaba con la convicción de quien conocía de cerca los casos. No dejaba de aceptar que los indios se fugaban, pero esas fugas no provenían de su propia dinámica sino de la presión externa. Los indios morían efectivamente, pero por el desánimo, por la inclemencia de los climas y por su pobreza. El mismo indio cuyos recursos se habían expropiado y cuya fuerza de trabajo se apropiaban los españoles, era un muerto en un informe o un idólatra en otro, dependiendo de si se lo ocultaba o de si se lo buscaba.

Alfaro, desde luego, hacía una larga evaluación para llegar a lo poco feliz que le parecía el arbitrio propuesto. Celoso defensor de su posición, demandaba más bien que se prohibiera de todas las maneras que ningún indio ni comunidad pudiera vender tierra alguna. Todas las formas que se usaban para pasar terrenos de indios a las crecientes propiedades de los blancos eran recusadas por Alfaro. Los testamentos de indios ricos e incluso las mandas para obras pías, que otras autoridades fácilmente apañarían, también eran objetados por este memorial. La opción de la corona era más bien volver a visitar los pueblos y señalar de nuevo las tierras por ayllus, sin que se entretejiesen unas propiedades de unos con las de otros, y menos con tierras de españoles. Los límites entre las repúblicas y la nece- 
saria «protección» del estado a los indios eran subrayados por Alfaro. Según él, en las tierras del común de los naturales nadie debía realizar enajenación alguna de forma inmediata; cuando algún indio muriese y quedaran vacantes las tierras, se debía certificar que el común no las necesitara $\mathrm{y}$, sancionada la vacancia, tendrían que pasar seis años antes de que se pudiesen enajenar.

Abundando en sus prevenciones protectoras y rectoras del manejo de los recursos por la sociedad india, Alfaro llegó a un punto en donde se excusaba de fundamentar legalmente sus argumentos, aduciendo que sería muy largo hacerlo - mucho más de lo extensa que ya era esta importante pieza del pensamiento pro indio de separación de repúblicas-, pero para despejar cualquier duda señalaba: «por mayor digo que los indios en tiempo del inca no tuvieron tierras, él se las daba y señalaba». Más claro no podía ser Alfaro; la norma de la práctica india debía mantenerse en la nueva situación, respetando la forma de conducción de los recursos. Incluso, no solo eso sino también que «VM tiene mandado que en cuanto no fuera contra la religión, se les guarde sus costumbres». Puro argumento de relatividad cultural, convivencia y paternalismo, que todavía tenía defensores sólidos. Pero entonces, la desestructuración de la sociedad india y el desarrollo de formas mercantiles que penetraron en el mundo indígena lo transformarían en algo muy diferente al sueño protector de los indigenistas.

Existía, sin embargo, la posibilidad de que los indios mismos quisieran vender sus posesiones como parte de sus haciendas, a las que tenían derecho como todos; quitarles la posibilidad de venta era quitarles su comercio podía aducirse. Alfaro afirmaba al respecto: «pregunto yo si es quitar el comercio hacer vínculos o si los que poseen bienes vinculados pierden por esto calidad, autoridad ni reputación». Así, usando los ideales de la propia sociedad española que presionaba por las tierras de los indios, rebatía la hipocresía del argumento contrario al suyo. Los indios, además, estaban enraizados en la tierra - «por que en ellos no se puede considerar otra raiz»—; su acercamiento a la tierra era otro al que tenían los españoles. Cuando se vendían las propiedades de los naturales, estos ya no las recuperaban y no se conocía indio que comprara tierras. Vender sus tierras era reducirlos a nada, por eso: «además de materia de estado también en rigor de justicia se puede prohibir a uno que no use mal de su hacienda». Concluía de este modo la lógica de la legislación protectora. Ese era el ideario de una de las corrientes de pensamiento colonial respecto a la forma de «civilizar» a los indios. Esta vez Alfaro escribía sobre las tierras, tema 
emparentado con el de las reducciones, «materia no tan invencible como los interesados la presentan», sobre la que giró el debate colonial de esta época.

\section{A modo de conclusión: del final del debate sobre los arbitrios de tierras al intento de subsanar los agravios de las composiciones}

Las otras respuestas al arbitrio de Hermosa muestran la existencia de tres posiciones al respecto. La Audiencia de Lima suscribía los términos de Alfaro, puesto que los oidores en cuerpo reconocían que la composición de 1593 había sido perjudicial para los indios. Aunque la determinación real no correspondía a tierras de indios así se interpretó, de manera que las visitas de composición terminaron «desacomodando» a los naturales. Fue, como se sabe, el conde del Villar el primero que avisó al Consejo de Indias acerca de la posibilidad de sacar utilidad de la formación de posesiones privadas, criterio que se aplicó finalmente durante el gobierno del marqués de Cañete. El discurso de la audiencia era más tibio que el de Alfaro, ya que no abordaba los procedimientos y dejaba la determinación al rey. En la línea de Alfaro, reconocía que la alternativa sería que se pudieran hacer composiciones en resguardo de los interes de la real hacienda pero, sobre todo, en resguardo de los derechos de los indios.

Por su parte, el Tribunal de Cuentas dió un parecer que sería el que oficialmente adoptaría Chinchón: que no se hicieran las composiciones propuestas puesto que resultarían en gran perjuicio de los indios, si es que antes no se realizaba la reducción general. Esa era la posición más clara, que fue apoyada implícitamente por el fiscal, Luis Henríquez, quien muy escuetamente señaló que había convocado a Ugarte que, sin embargo, no había acudido. De este modo, no dio su opinión salvo que «lo que no corre por mano de oidor o persona tal, solo sirve de daño público e interés particular». Mostraba así la poca simpatía que tenía por la intromisión de arbitristas y buscadores de oficios. Finalmente, el contador Bartolomé de Osnayo, que había tenido una larga experiencia de tributos y reducciones en Chucuito, opinó muy en contra de la sociedad india, avalando la necesidad de la reducción como medida punitiva y fiscalizadora. En cambio, no daba parecer alguno respecto de la composición. Osnayo decía, siguiendo la opinión que se manejaba en la mayoría de círculos gubernamentales de 
españoles o criollos, que los pobladores andinos eran naturalmente flojos y que las fugas de la reducción provenían de la «malicia» que habían desarrollado. Por eso proponía como la tarea más importante la reducción y señalaba el procedimiento: el mismo virrey debía hacerla.

La tercera posición era la de los españoles que controlaban el mercado y el poder regionales. Quien opinó al respecto fue don Pedro Jarava, cabeza de un grupo familiar de honda ramificación en la corte metropolitana que había controlado Chucuito, el más rico corregimiento del reino, por proveimiento real concedido durante varias décadas. ${ }^{21}$

Sea por la oposición al arbitrio o por el señalamiento de la reducción como tarea primaria, el debate dejó en ascuas la medida. Pero no era esa la tendencia que se consolidaría, tanto por la necesidad de la corona y las políticas que implementó frente a ella, como por la misma dinámica del mercado de tierras en el virreinato. Así, el arbitrio se enmendó en Madrid y se envió nuevamente al Perú. Una real cédula al conde de Chinchón de 27 de mayo de 1631 se remitió para que se procediese a hacer una nueva composición, respetando a los poseedores de justos títulos. A quienes se hubiesen introducido en demasía, se les concederían nuevos con moderada composición, y las tierras que estuvieran absolutamente por componer se rematarían públicamente.

La cédula consideraba que había un arbitrio para la composición de tierras con el que se quería contribuir a la financiación de los gastos de la corona, y reconocía que muchas propiedades estaban compuestas a muy bajos precios. Por lo tanto, sugería que se hiciera una nueva venta para el mayor beneficio de los vasallos. El texto no partía de la negación de los abusos aunque no decía nada de los indios. Más bien, hubo una cédula de la misma fecha para que el rey tomara prestadas cantidades que se guardaban en las cajas de las comunidades indígenas. Entre los arbitrios que fueron al Perú con Hernando de Valencia en 1631 había de todo, como incitar a los indios a descubrir las minas de oro y plata que tuvieran escondidas, la venta de oficios y la petición de servicios. ${ }^{22}$ Sin embargo, esta no fue la última arremetida arbitrista; una propuesta de García de Tamayo se recibió el 6 de mayo de 1637. Este arbitrio prometía sacar 40.000 pesos de beneficio por la venta de tierras que estaban libres. Esta vez sí se recomendaba que

21 Glave, 2009, 338.

22 AGI, Indiferente, 2689. El texto de las cédulas se puede consultar en AGI, Indiferente, 429, libro $37,227-252$. 
se oyese al protector y al letrado de los indios, y que se consultase teniendo presente que no debía resultar «daño considerable» a los naturales.

Con todo, la política de composiciones se implementó desde 1639 arrojando resultados extremos contra los indios, aunque esa ya es otra historia. El 23 de mayo de 1651 se otorgó una cédula dando aviso al virrey y a la audiencia de Lima de lo que se había resuelto ejecutar para el desagravio de los indios en la venta y composición de tierras, de donde resultaron nombrados connotados religiosos como nuevos jueces en 1654. Previamente, otra real cédula de 30 de octubre de 1648 había ordenado al virrey que suspendiese la venta de los terrenos y que formase en la audiencia de Lima una sala de justicia que averiguase los excesos y los fraudes que hubiesen cometido los jueces que realizaron las enajenaciones y las composiciones. La junta procedió en los asuntos de justicia que se habían ofrecido en esta materia, y prestó particular atención al fiscal protector sobre la restitución de las tierras de las que habían sido despojados los indios. Nuevamente se quiso enmendar un proceso de despojo permanente que los esfuerzos legales y políticos por impedirlo no lograron evitar.

Recibido el 5 de febrero de 2014

Aceptado el 6 de abril de 2014

\section{Bibliografía}

Amadori, Arrigo: «Privanza, patronazgo y fiscalidad indiana en la corte de Madrid durante el reinado de Felipe IV», Revista Complutense de Historia de América, 34, Madrid, 2008, 63-84.

Amadori, Arrigo: «Fiscalidad y consenso en el virreinato de Perú, 1620-1650», América Latina en la Historia Económica, 19-2, México, 2012, 7-45.

Amadori, Arrigo: «No es menos servicio el diferir que el ejecutar. El programa fiscal de Felipe IV para el Perú y la gestión del virrey Chinchón (1629-1641)», Historia, 46-I, Santiago de Chile, 2013, 7-37.

Bronner, Fred: «Tramitación legislativa bajo Olivares. La redacción de los arbitrios de 1631», Revista de Indias, XLI/165-166, Madrid, 1981, 411-444.

Bronner, Fred: «Peruvian Arbitristas under Viceroy Chinchon, 1629-1639», Studies in Hispanic History and Literature, XXVI, 1977, 34-78.

Dougnac Rodríguez, Antonio: «Un jurista indiano en la ruta de Hobbes», Revista chilena de Historia del Derecho, 17, Santiago de Chile, 2012, 29-55.

Fox, K.V.: «Pedro Muñiz, Deán of Lima, and the Indian Labor Question», Hispanic American Historical Review, 42-1, Durham, 1962, 63-88. 
Glave, Luis Miguel y Remy, María Isabel: Estructura agraria y vida rural en una región andina. Ollantaytambo entre los siglos XVI-XIX, Cuzco, Archivos de Historia Andina, 1983.

Glave, Luis Miguel: «Propiedad de la tierra, agricultura y comercio, 1570-1700: el gran despojo», en Contreras, Carlos (ed.), Compendio de historia económica del Perú, II: Economía del período colonial temprano, Lima, Banco Central de Reservas del Perú - Instituto de Estudios Peruanos, 2009, 313-446. 